Available online on 15.10 .2020 at http://jddtonline.info
Open Access to Pharmaceutical and Medical Research

Open $\odot$ Access

Research Article

\title{
Sperm Profile of Infertile Men in the Western Region of Algeria: About 320 Cases
}

\author{
Anissa FIZAZI ${ }^{*}$, Malika BENDAHMANE${ }^{2}$, Tewfik SAHRAOUI ${ }^{1}$ \\ ${ }^{1}$ Biology of Development and Differentiation Laboratory, Department of Biology, Faculty of Natural and Life Sciences, University of Oran1, \\ Ahmed Ben Bella, Algeria \\ ${ }^{2}$ Laboratory of Research on Environment and Health (LRES), Faculty of Medicine, Hospital University of Sidi Bel Abbes, Algeria
}

\begin{abstract}
Objective : The aim of this study is to describe the sperm profile and eventually determine the main spermatic disturbances at the origin of male infertility in western Algeria.

Methods: We conducted a cross-sectional study in 320 infertile male patients consulting at the Medically Assisted Procreation Unit (MAP) of Oran, in Western Algeria, in the end of exploring the results of their semen analyses and semen culture.

Results: The results of semen analysis revealed that the main spermatic disruption in our study was asthenospermia because at the first hour after emission, $93 \%$ of our patients had less mobility than normal.

Oligospermia was present in $37 \%$ of cases and azoospermia in $14 \%$ of cases. That is, a concentration of sperm below normal in $51 \%$ of cases.

Results of the analysis of the sperm's morphological characteristics revealed that only $16 \%$ of our patients had teratospermia.

The semen culture revealed that the main pathogen found in our patients is Staphylococci in nearly $70 \%$ of cases.
\end{abstract}

Conclusion: Our study revealed alterations in both quantitative and qualitative semen of patients. This was mainly asthenospermia in $93 \%$ of cases followed by oligospermia.

Keywords: Male infertility, Semen analysis, Semen culture, Western Algeria.

Article Info: Received 07 Aug 2020; Review Completed 13 Sep 2020; $\quad$ Accepted 18 Sep 2020; $\quad$ Available online 15 Oct 2020

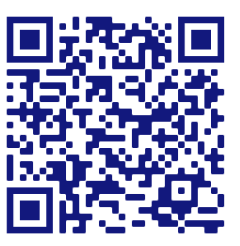

Cite this article as:

Fizazi A, Bendahmane M, Sahraoui T, Sperm Profile of Infertile Men in the Western Region of Algeria: About 320 Cases, Journal of Drug Delivery and Therapeutics. 2020; 10(5-s):51-56 http://dx.doi.org/10.22270/jddt.v10i5-s.4426

*Address for Correspondence:

Anissa FIZAZI, Biology of Development and Differentiation Laboratory, Department of Biology, Faculty of Natural and Life Sciences, University of Oran1, Ahmed Ben Bella, Algeria

\section{INTRODUCTION}

What defines infertility, according to the World Health Organization (WHO), is the absence of pregnancy after at least 12 months of regular and unprotected sexual intercourse 1 . Infertility affects around $15 \%$ of couples worldwide $^{2}$. Epidemiological data suggests that roughly 48.5 million of couples having regular sexual intercourse suffer from it in the world 3 . Infertility rates in Africa are the highest in the world: it would affect between $15 \%$ and $30 \%$ of couples, against $5 \%$ to $10 \%$ in Europe 4 . Men are the only responsible of infertility in 20 to $30 \%$ of cases, and contribute to $50 \%$ of mixed infertility cases 5 .

We speak of male infertility in the presence of poor quantity, mobility, morphology or functioning of sperm 6 . A man of the
2000 's produces half the sperm of his own father, a decrease of $2 \%$ per year 7 .

The assessment of male infertility lies on a series of examinations; the semen examination proves to be a very good basic examination, allowing not only to make diagnoses, but also to direct the prescriber to additional examinations ${ }^{8}$.

We estimate Algeria's infertility rate at $15 \%$, and the men are the cause of this infertility in more than half of the cases ${ }^{9}$.

However, there is unfortunately a great lack of data and studies on male infertility in Algeria.

In this context, we have conducted a study in order to describe the sperm profile in western Algeria and eventually 
determine the main spermatic disturbances at the origin of this major public health problem.

\section{PATIENTS AND METHODS}

We carried out a cross-sectional descriptive study at the Medically Assisted procreation Unit (MAP) of Oran. We explored the results of sperm count, sperm cytology and bacteriological examination of sperm carried out in 320 infertile patients aged between 18 and 83 years.

We included in our survey all spermograms of patients with fertility problems regardless of their age. Spermograms from men who did not have fertility problems were excluded from our study.

These examinations enabled measuring with precision the various spermatic parameters such as the volume of the sperm, its viscosity and its $\mathrm{pH}$, the number of spermatozoa, their mobility, their vitalities and their morphologies.

After collection, the sperm is stored in an oven at constant temperature, $37^{\circ} \mathrm{C}$, during the whole examination. We must then evaluate the liquefaction time; it is normally less than 30 minutes.

The $\mathrm{pH}$ volume is measured using a graduated container. The $\mathrm{pH}$ will be measured on a paper strip $\mathrm{pH}$ indicator (measuring scale 6-10 pH units) checked within one hour of sampling.

The viscosity is evaluated semi qualitatively by observing the way in which the sperm flows at the end of the pipette. It is normal if the semen flows in the form of well-separated drops, and it is increased when it forms filaments (unseparated drops).

We study global mobility and progressive mobility (spermatozoa crossing the microscope field) at emission and 4 hours after.

We study vitality within an hour of sampling. The vitality of sperm is studied using a mixture of equal parts of sperm with eosin and nigrosine. We observe the slide under a microscope $(\mathrm{x} 40)$, the living sperm are white, the dead are red.

A drop of sperm, placed between slide and coverslip, is observed under a microscope ( $\mathrm{x} 40$ ), this direct examination allows the assessment of abnormal elements: germs, bacteria, round cells, aggregates, agglutinates.
The numeration of sperm (and possibly round cells) is carried out using a Malassez cell after liquefaction of the seminal clot. We use this total numeration in the laboratory to interpret spermograms.

The morphological study of sperm is carried out on a smear that is made up from the semen, fixed and then stained with May-Grunwal-Giasma (MGG). The slide is mounted and examined at the highest magnification (objective 100), with immersion. The outcome is revealed with two numbers, for example: $15 / 100$ means that there are fifteen morphologically abnormal sperm.

The semen culture will enable the search for the infectious agents implicated in the genital tract infections.

The performance of the bacteriological examination includes:

- A direct Gram test in the fresh state of sperm between slide and coverslip, which will aim to search for the presence of yeasts or parasites. We can use Gram stain to test for the existence or not of Gram-negative diplococci, yeasts, Grampositive cocci, Gram-negative bacilli. MGG staining helps note the presence or absence of leukocytes.

- Culture after dilution to the 10th of the sperm in physiological serum, the sample is sown on a chocolate agar, an aerobic and anaerobic blood agar and a Sabouraud agar for the detection of yeasts.

The results of the spermograms were interpreted according to the criteria of the WHO version 2010 (WHO, 2010) ${ }^{10}$.

The SPSS 20.0 software (Statistical Package for the Social Sciences, IBM Corporation; Chicago, IL, August 2011) for Windows allowed us to make a descriptive analysis of each variable through average calculations with standard deviation, frequency and percentage.

\section{RESULTS}

\section{Age of Patients}

Analysis of the results shows that the average age of our study population was $40.39 \pm 7.59$ years with extremes ranging from 24 to 83 years. Figure 1 shows our sample broken down by age group. It is important to note that more than two thirds of our patients (73.42\%) were over 35 years old; the most represented age group is that of 36-45 years old, it alone represents half of our sample.

The data collected also specifies that the average age of marriage of our patients was $35.19 \pm 3.80$ years.

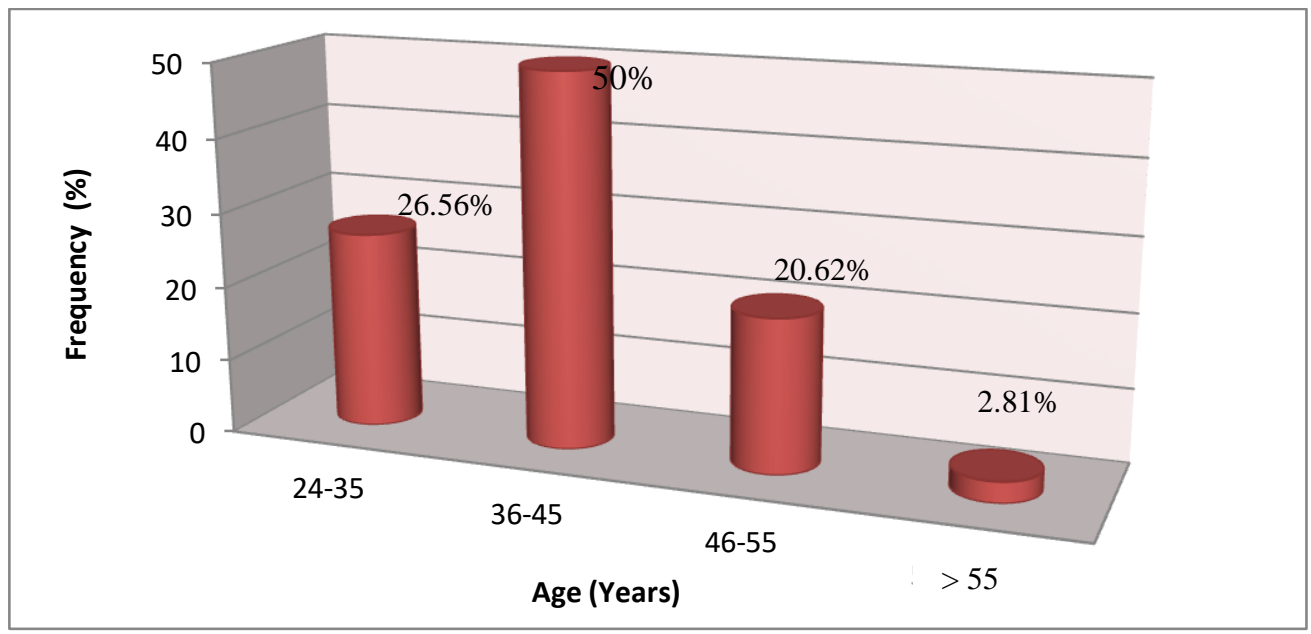

Figure 1: Distribution of patients according to their age group. 


\section{Results of spermograms}

The results of the sperm analysis specifying the various sperm parameters such as sperm volume, viscosity and $\mathrm{pH}$, sperm numeration, their mobility and vitality are presented in Table 1.

Table 1: Distribution of patients according to the results of the semen analysis

\begin{tabular}{|c|c|c|c|}
\hline & & Workforce & Percentages \\
\hline \multirow{3}{*}{$\begin{array}{l}\text { Ejaculatory volume } \\
(\mathrm{mL})\end{array}$} & $<1.5$ & 56 & $17.64 \%$ \\
\hline & {$[1.5-6]$} & 255 & $79.63 \%$ \\
\hline & $>6$ & 9 & $2.71 \%$ \\
\hline \multirow[t]{3}{*}{ Viscosity } & Decreased & 26 & $8 \%$ \\
\hline & Normal & 250 & $78 \%$ \\
\hline & Increased & 44 & $14 \%$ \\
\hline \multirow[t]{3}{*}{ pH } & $<7.2$ & 43 & $15 \%$ \\
\hline & {$[7.2-8]$} & 194 & $65 \%$ \\
\hline & $>8$ & 59 & $20 \%$ \\
\hline \multirow[t]{6}{*}{ Numeration of sperm $(\mathrm{M} / \mathrm{mL})$} & 0 & 44 & $13.66 \%$ \\
\hline & $<5$ & 61 & $19 \%$ \\
\hline & [5-15] & 58 & $18 \%$ \\
\hline & ] $15-20[$ & 19 & $6 \%$ \\
\hline & {$[20-200]$} & 135 & $42 \%$ \\
\hline & $>200$ & 3 & $1 \%$ \\
\hline \multirow{3}{*}{$\begin{array}{l}\text { Sperm mobility at the first hour } \\
(\%)\end{array}$} & 0 & 24 & $7.50 \%$ \\
\hline & $<40$ & 274 & $85.50 \%$ \\
\hline & $\geq 40$ & 22 & $7 \%$ \\
\hline \multirow{3}{*}{$\begin{array}{l}\text { Sperm mobility at the fourth } \\
\text { hour (\%) }\end{array}$} & 0 & 93 & $29 \%$ \\
\hline & $<40$ & 224 & $70 \%$ \\
\hline & $\geq 40$ & 3 & $1 \%$ \\
\hline \multirow[t]{2}{*}{ Vitality (\%) } & $\leq 58$ & 161 & $50.50 \%$ \\
\hline & $>58$ & 159 & $49.50 \%$ \\
\hline
\end{tabular}

The study of spermograms showed that the volume of the ejaculate was normal in nearly $80 \%$ of cases (Table 1 ) and the average volume was $2.76 \pm 1.58 \mathrm{~mL}$, with extremes ranging from 0 to $8.50 \mathrm{~mL}$.

Analysis of the semen's appearance in our patients shows normal viscosity in $78 \%$ of cases (Table 1). For the $22 \%$ of cases who had abnormally viscous sperm, it was high viscosity in $14 \%$ of cases and decreased viscosity in $8 \%$ of cases.

The study of the $\mathrm{pH}$ measurement shows that the average pH was $7.90 \pm 0.72$ (Min: 1.5 - Max: 10).

In our study, the $\mathrm{pH}$ in the normal range $(\mathrm{pH}=7.2$ to 7.8$)$ represented $65 \%$ of cases. Otherwise, it was $\mathrm{pH}$ below 7.2 in $15 \%$ of cases and above 8 in $20 \%$ of patients.

Measuring the sperm concentration per millions (M) in one $\mathrm{mL}$ of ejaculate has shown that only $49 \%$ of cases have a normal numeration. $37 \%$ of our patients were diagnosed of oligospermia. It was severe oligospermia in $19 \%$ of cases, and nearly $14 \%$ was azoospermic (Figure 4) while the average sperm concentration is $31 \pm 42 \mathrm{M} / \mathrm{mL}$ (Min: 0 Max: 224).

The study of sperm mobility revealed that at the first hour after emission, only $7 \%$ of patients had normal mobility, and the average mobility was $17.40 \pm 15.88$ with extremes ranging from 0 to $81 \%$ (Table 1 ). This average dropped by $50 \%$ at the fourth hour and moved to $8.36 \pm 9.95$ (Min: 0 Max: 70 ) with only $1 \%$ of normal mobility cases (Table 1 ).

Analysis of sperm vitality in our population revealed an average vitality of $54 \pm 25.56 \%$ (Min: 2 - Max: 98) with $50.50 \%$ of necrospermia cases (Table 1 ).

Results of the analysis of the sperm's morphological characteristics revealed that the average typical sperm shape was $51 \pm 30.37 \%$ (Min: 0 - Max: 98) with only $16 \%$ $(n=51)$ of teratospermia cases (Figure 2). 


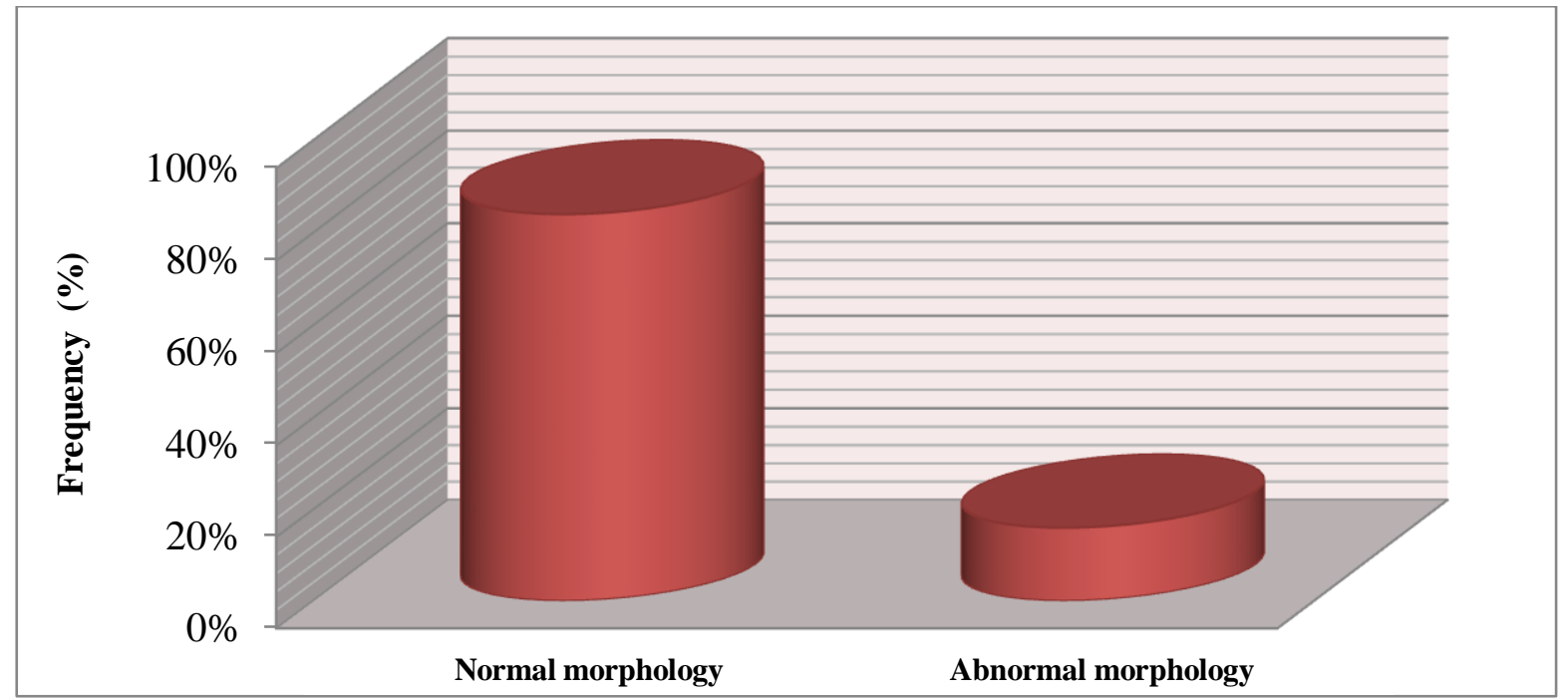

Figure 2: Distribution of patients according to their sperm morphology

\section{Result of semen culture}

A considerable portion of our patients suffered from genital tract infection. Often asymptomatic, the latter results from aggression by various germs. We carried out a bacteriological examination (Semen culture) on the patients in order to identify the pathogens involved.
The germs found during this examination show in figure 3. It appears that Staphylococci are responsible for these infections in nearly $70 \%$ of cases, followed by Streptococci and $E$. coli with frequencies of 11 and $8 \%$ respectively.

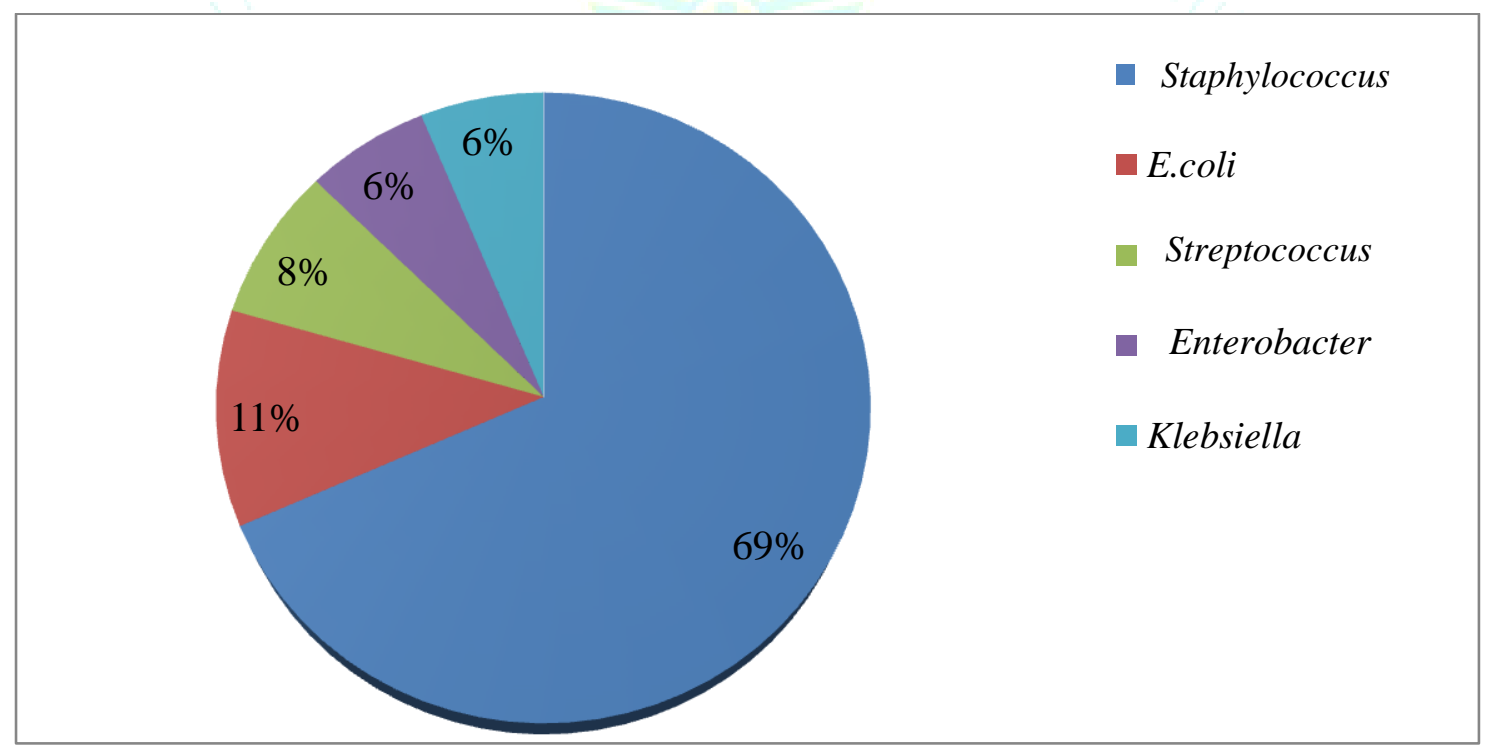

Figure 3: Distribution of patients according to the results of their semen culture.

\section{DISCUSSION}

The advanced age of our population ( $40.39 \pm 7.59$ years) is due to late marriage in urban areas due to the length of studies, lack of work and financial means.

In 2002, Algerian men married on average after 30 years and one in two men was still single at 30-34 years. This spectacular rise in celibacy is associated with factors of crisis and poverty such as unemployment and the housing shortage ${ }^{11}$.

This increase in the age of our patients could be associated with the decline in their fertility, which is in agreement with the results of the study carried out by Larochebrochard et al.
(2003) who found that paternal age over 40 is a key risk factor for infertility 12 .

In our sample, the vast majority of patients $(73.42 \%)$ were over 35 years old, which could be the cause of the deterioration of their spermograms.

Our results match with those of a meta-analysis of 20 studies spanning from 1980 to 1999 (Kidd et al., 2001). The latter has shown a decrease in sperm volume and mobility with age ${ }^{13}$.

During our study, $80 \%$ of patients had a spermogram of normal volume, i.e. between 1.5 and $6 \mathrm{~mL}, 17 \%$ had hypospermia with a volume lower than normal and $3 \%$ of 
our patients had hyperspermia with a sperm volume greater than $6 \mathrm{~mL}$.

These results are almost similar to those obtained in 2015 in another city in western Algeria (Sidi Bel Abbes) ${ }^{14}$. This decrease in sperm volume can be explained in our study either by a dysfunction of the prostate and seminal vesicles or by a problem of incomplete collection of sperm or the non-observance of the abstinence period by the patient $(24$ to 48 hours).

The increase in sperm volume ( $>6 \mathrm{ml})$ can also have other causes in our specific case, either a simple prolongation of the abstinence period (more than 5 days of abstinence) not reported by the patient, or by the accumulation of two to three ejaculates in the flask. It is that for several patients, the first ejaculate alone risks showing inadequacies in the result.

The volume criterion seems to be a predictor of fertility problems. Hyperspermia could be explained either by prolonged abstinence or by the presence of an infection of the annex glands ${ }^{15}$. In addition, Mamor (1993) has proved that this increase in sperm volume can also contribute to infertility, by dilution of spermatozoa and a too rapid evacuation of sperm during intercourse ${ }^{16}$.

As for hypospermia, it can be due either to a loss of part of the ejaculate 17 or to incomplete ejaculation due to a dysfunction of the ejaculatory reflex ${ }^{18}$. Or else to insufficient secretions of one or the other of the annex glands (a situation that may correspond to prostatitis or vesiculitis), or exclusion of seminal vesicles (congenital or acquired) where there will be azoospermia and the volume will generally be less than $1 \mathrm{~mL}^{19}$.

Considering the interaction between seminal plasma and sperm, one can easily imagine a deleterious effect on mobility and fertilization power in these patients ${ }^{20,21}$.

We found that $78 \%$ of patients had normal sperm viscosity. For the $22 \%$ of patients who had abnormally viscous sperm, this was high viscosity in $14 \%$ of cases and decreased viscosity in $8 \%$ of cases. A very high viscosity could indicate prostatic dysfunction.

In our study, $35 \%$ of patients had an abnormal $\mathrm{pH}$, this was acidic in $15 \%$ of cases and alkaline in $20 \%$ of cases.

The pH alkalinity can be explained as has been reported in the literature by prostatic insufficiency or by the presence of infection. Whereas the $\mathrm{pH}$ acidity is due to seminal vesicular dysfunction or sometimes to incomplete collection of sperm $^{22}$.

The results of the spermograms reveal that in our series, the most frequent spermatic disturbance is asthenospermia; its frequency is $93 \%$ at the 1st hour after emission and $99 \%$ at the 4 th hour, which is extremely worrying.

Asthenospermia is due either to an infectious phenomenon and / or an absence of fructose 23 .

In our sample, Asthenospermia is followed by oligospermia, which was present in $37 \%$ of cases and azoospermia in $14 \%$ of cases. That is, a sperm concentration of less than 15M / $\mathrm{mL}$ in $51 \%$ of cases.

The spermatic disturbances revealed by our study are greater than the ones obtained by Zeghib (2009) where asthenoteratospermia represented $33.33 \%$ of cases and oligo-astheno-teratospemia (OATS) represented $20.37 \%$ of cases ${ }^{24}$.

On the other hand, the rate of azoospermia in his series was $17.59 \%$, a rate higher than the one found in our study ${ }^{24}$.
Furthermore, Samba (2003) demonstrated that in 335 patients, $23.5 \%$ presented oligospermia and $55.9 \%$ oligoasthénospermia compared to our results 25 .

Necrospermia occupies an important place with $50.50 \%$ of cases while teratospermia was only present in $16 \%$ of cases. This result differs from that obtained by David et al. (2001), where only $9 \%$ of infertile patients had normal sperm morphology 26 .

The semen culture revealed that the main pathogens incriminated in these infections in our patients are Staphylococci.

This result corroborates with that of Momoh and al. who claim that Staphylococci are the predominant pathogens in male infertility associated with infections of the male genital tract 27 .

Mogra and al. also found that the pathogenic germs in their population were mainly Staphylococci and Streptococci; they were present in $65 \%$ of cases $^{28}$.

Non-specific infection of the genital tract could be an important cause of male infertility ${ }^{16}$. According to Ogunbanjo and al., Infections can affect fertility in several ways: deterioration of sperm by altering sperm mobility and the chemical composition of seminal fluid or by causing an inflammatory process in the male genital tract 29 .

\section{CONCLUSION}

A spermogram is the biological test of semen, which is considered the key biological test in the first-line assessment and investigation of male infertility. In our study, this key examination revealed both quantitative and qualitative alterations in the sperm of our patients. It was mainly asthenospermia in $93 \%$ of cases followed by oligospermia and necrospermia.

Finally, a more in-depth study aimed at identifying the factors that are at the origin of these spermatic alterations in our population turns out to be necessary.

\section{ACKNOWLEDGMENTS}

We express our gratitude to the staff of MAR unit of Oran (Algeria) for their skilled technical assistance. We are grateful to HADJARI Meriem for English language revision.

\section{CONFLICT OF INTEREST : No.}

\section{REFERENCES}

1. World Health Organization, "WHO Manual for the Standardized Investigation, Diagnosis and Management of the Infertile Male", Cambridge University Press, 2000: 91.

2. Sharlip ID, Jarow JP, Belker AM, Lipshultz LI, Sigman M, Thomas AJ, et al. "Best practice policies for male infertility ${ }^{2}$ Fertil Steril, 2002; 77:873-882.

3. Martinez G, Daniels K, Chandra A, "Fertility of men and women aged 15-44 years in the United States: National Survey of Family Growth, 2006-2010" Natl Health Stat Report, 2012; 51:1-28.

4. Rombert H, "Infertilité : un couple ivoirien raconte son bébééprouvette" Le monde, 2016.

5. Agarwal A, Mulgund A, Hamada A, et al. "A unique view on male infertility around the globe” Reprod Biol Endocrinol, $2015 ; 13: 37$.

6. McElreavey K, Krausz C, Patrat C, Fellous M, “Infertilité masculine et les microdélétions du chromosome Y, Male infertility and microdeletions of the Y chromosome " Gynécologie Obstétrique \& Fertilité, 2002; 30(5):405-412. 
7. Slama R, Jegou B, Cordier S, “ Nouvelles avancées dans l'étude de l'influence de l'environnement sur la santé reproductive masculine" Revue épidémiologique de santé publique, 2006; 54:167-174

8. Dohle GR, Colpi GM, Hargreave TB, Papp GK, Jungwirth A, Weidner W, "EAU Guidelines on male infertility European" Urology, 2005; 48:703-711.

9. Fizazi A, Bendahmane M, Elhaina FZ " Etiology and Toxic Factors Involved in Male Infertility in Western Algeria” South Asian Journal of Experimental Biology (SAJEB). 2016; 5(5):174-178.

10. WHO, Laboratory manual for the Examination and Processing of Human Semen. Fifth édition; 2010.

11. Ouadah-Bedidi $\mathrm{Z,} \mathrm{"} \mathrm{Avoir} 30$ ans et être encore célibataire : une catégorie émergente en Algérie" Presses de Sciences Po (P.F.N.S.P), 2005; 2(34):29 - 49.

12. Larochebrochard E, Thonneau $P$ "Paternal age $>$ or $=40$ years: an important risk factor for infertility " Obstet Gynecol. 2003; 189:901-905.

13. Kidd SA, Eskenazi B, Wyrobek AJ, "Effects of male age on semen quality and fertility: a revieuw of the literature" Fertil. Steril, 2001; 75: 237-248.

14. El-haina FZ, Bendahmae M, Fizazi A, Zerrouki R, Kandouci, “ A Effet des facteurs médicaux et environnementaux sur la morphologie des spermatozoïdes chez les hommes infertiles à l'ouest Algérien " Afrique science, 2015; 11(4):150-165.

15. Mekhatri A, Benamar N. Le couple stérile. Edition : Dar elgharb ; 2006. P. 25-35.

16. Mamor D, "Anomalie du volume de l'éjaculat polyzoospermie" Andrologie, 1982; 38 (5):181-185.

17. Girod C, Czyba JC. Biologie de la reproduction. Simep édition ; 1976. P.11 - 120 .

18. Robin G, Marcelli F, Mitchell V, Marchetti C, Lemaitre L, Dewailly D, et al. "Pourquoi et comment réaliser un bilan d'hypospermie ? " Gynécologie Obstétrique \& Fertilité, 2008; 36(10):1035-1042.

19. Guerin JF, “Le sperme normal”. La Revue du praticien, 1993; 43(8):932-935.

20. Newman HF et al. "Physical basis of emission, ejaculation, and orgasm in the male" Urology, 1982; 19(4):341-350.

21. Glezerman M et al. "Polyzoospermia: a definite pathologic entity" Fertility and Sterility, 1982; 38(5):605-608.

22. Okonofua F, “Les Nouvelles Technologies Reproductives et le Traitement de la Stérilité en Afrique" La Revue Africaine de la Santé Reproductive , 2003; 7(1):7-11

23. Hamamah S, Barthelemy C. Spermogramme et tests de fécondance : intérêt et limites ; 1997.P.1-6.

24. Zeghib F. Les infertilites masculines : étude cytologique et biochimique. Thèse en ligne : université des fréres Mentouri Constantine $1 ; 2009$.

25. Ron-El R, Raziel A, Strassburger D, Schachter M, Kasterstein E, Friedler S, "Outcome of assisted reproductive technology in women over the age of 41" Fertil Steril, 2000; 74(3):471-475

26. David S, James W, Charlene K, Steven T, Michael P, Joseph A, et al. "Sperm morphology, motility, and concentration in fertile and infertile men" N Engl J Med, 2001; 345(19):1383-1393.

27. Momoh ARM, Idonije BO, Nwoke EO, Osifo UC. Okhai O, Omoroguiwa A, et al. "Pathogenic bacteria-a probable cause of primary infertility among couples in EkpomaJ " microbiol. Biotech. Res, 2011; 1(3):66-71.

28. Mogra N, Dhruva A, Kothari LK, “ Non-specific seminal tract infection and male infertility: a bacteriological study" Journal of Postgraduate Medicine, 1981; 27(2):99-104.

29. Ogunbanjo BO, Osobaa O, Ochei J, "Infective factor of male infertility among Nigerians” Afr. J. Med. Sci., 1989; 18: 35-38. 